\title{
Transverse vaginal septum with menouria and unilateral renal agenesis-case report
}

\author{
Baafuor Kofi Opoku ${ }^{1,2^{*}}$, Richard Owusu Kwarteng ${ }^{2}$ and Philip Agyeman Prempeh ${ }^{2}$
}

*Correspondence: baafuoropoku@yahoo.com

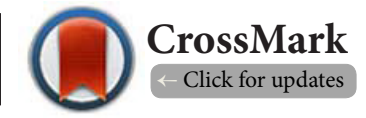

'School of Medical Sciences, Kwame Nkrumah University of Science \& Technology, Kumasi, Ghana.

${ }^{2}$ Department of Obstetrics \& Gynecology, Komfo Anokye Teaching Hospital, Kumasi, Ghana.

\begin{abstract}
Transverse vaginal septum is a rare condition that results from abnormalities in the vertical fusion between the vaginal components of the Mullerian ducts and the urogenital sinus. Associated menouria as a result of a fistulous connection of the vagina with the bladder is even rarer. A case is presented of a 22 year old unmarried woman who in addition to presenting with primary amenorrhea, complete transverse vaginal septum and cyclic hematuria, also had unilateral renal agenesis and a corrected congenital imperforate anus. A surgical correction is described as well as simple measures during follow-up that ensured non-contracture of the excision site. The fistulous connection between the bladder and upper vagina closed spontaneously. The patient has since been having normal menses for the past 15 months with no associated hematuria. The vagina has remained patent since. We conclude that for cases of transverse vaginal septum associated with menouria excision of the septum that ensures normal outflow of menstrual blood is sufficient to facilitate spontaneous closure of the fistulous connection between the bladder and vagina.
\end{abstract}

Keywords: Transverse vaginal septum, mullerian duct abnormalities, cyclic hematuria, condom packs

\section{Background}

Transverse vaginal septum (TVS) is a rare condition that results from abnormalities in the vertical fusion between the vaginal components of the Mullerian ducts and the urogenital sinus [1]. The septum usually varies in thickness and may be located at any level in the vagina, although most are found in the upper and mid-vagina $[2,3]$. The reported incidence is 1 in 50,00070,000 females $[4,5]$.

Clinical presentation of a TVS depends on whether it is complete or partial. With complete septa, menstrual blood accumulates and distends structures above the septum after puberty. This results in hematocolpos and hematometra. Such patients usually present with cyclic lower abdominal pain and ultrasonic findings of hematocolpometra. Occasionally a lower abdominal mass (hematometra) may be palpable. Incomplete septa allow partial outflow of menstrual blood. Such patients usually present with cryptomenorrhea, dysmenorrhea and dyspareunia.

TVS is also known to be associated with imperforate anus, bicornuate uterus, coarctation of the aorta, atrial septal defect and malformation of the lumbar spine in $37-60 \%$ affected females [6].
Transverse vaginal septum with a urinary-vaginal fistula is even rarer, with a search of the literature reporting only 15 cases [7-10]. We present a case of a 22 year old woman who presented with primary amenorrhea and cyclical hematuria to Komfo Anokye Teaching Hospital, a tertiary hospital in Kumasi, Ghana.

\section{Case presentation}

Miss G.D, a 22 year old nulligravid, unmarried woman was referred from the hospital's polyclinic as a case of primary amenorrhea and hematuria in June 2013 to the specialist consulting room. She had first noticed hematuria when she was 17 years old. She had never menstruated and had noticed an abnormality in her genitals. The hematuria has been cyclical since the first episode, the last one being 3 weeks prior to presentation. She had no associated lower abdominal pain. She had been told by her mother that she could not pass feces at birth and had had to undergo two surgical procedures when she was a baby to correct that.

She looked well on general examination. She had normal female features and well-developed breasts-Tanner Stage 5 . Her blood pressure was normal as well as her heart sounds. The 
abdomen showed an ugly left paramedian, supra-umbilical scar (probably a colostomy scar). There was no palpable mass or tenderness. She had normal female hair distribution. The vulva looked normal. The vagina was shallow limited by a complete low transverse septum (Figure 1) and admitting the examining fingers to a depth of $1.5 \mathrm{~cm}$. The anus looked gaped, but a rectal examination revealed a circular tightening proximal to the anal orifice. A diagnosis of Complete Transverse Vaginal Septum and Cyclic Hematuria was made. She was put on hematinics, asked to retrieve her old folder and scheduled for a review in 2 weeks' time.

\section{Investigations}

She was reviewed as scheduled with an $\mathrm{Hb}$ of $12.1 \mathrm{~g} / \mathrm{dl}$. There was no abnormality in the other parameters of the full blood count. The liver and renal function test results were normal. Urinalysis showed no bacteria or ova. An abdomino-pelvic ultrasound scan showed a normal size uterus with normal endometrial plate. There was no hematometra. There was small fluid in the vagina that communicated with a similar pool in the pouch of Douglas (POD). There was no obvious communication with the bladder (Figure 2). The hospital's records department could not retrieve her old folder.

Examination in theatre during her next episode of hematuria
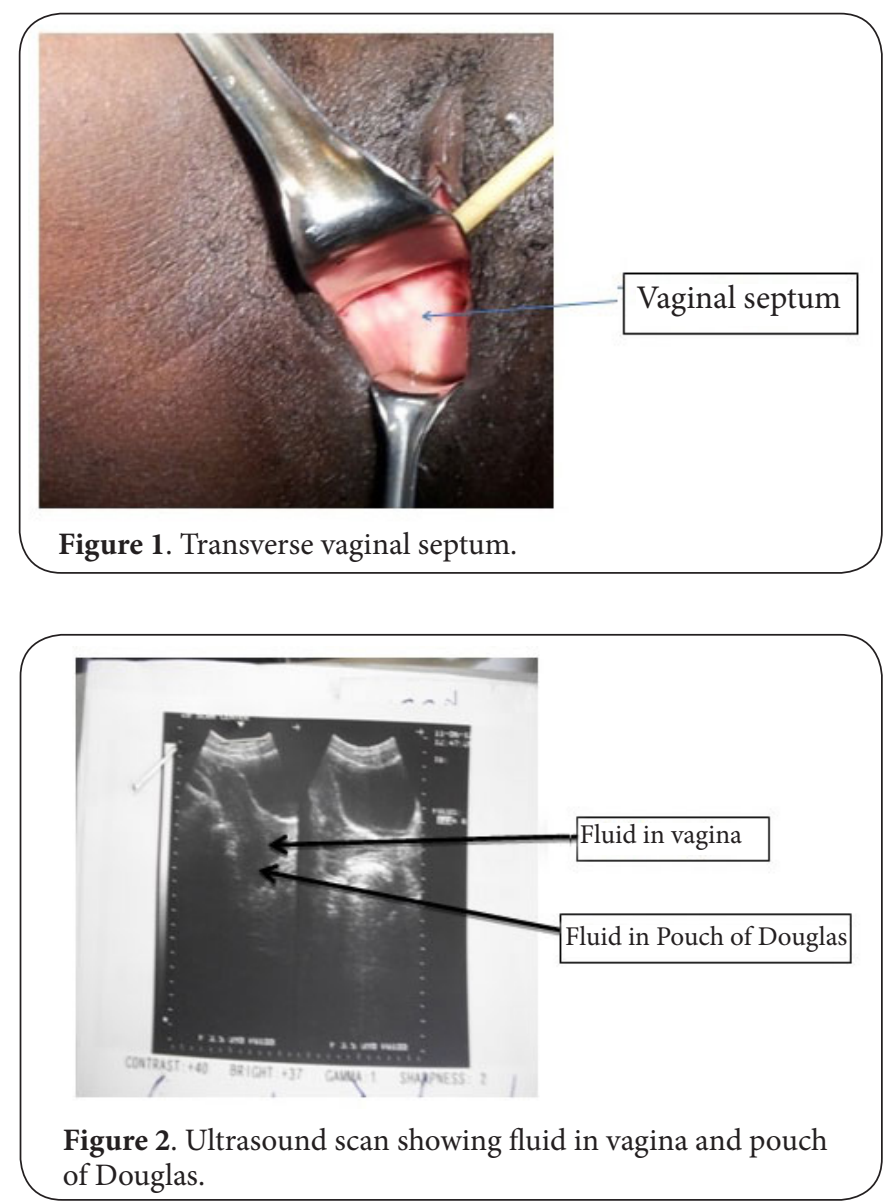

confirmed the previous vaginal findings. There was no bleeding per urethram but catheterization yielded $160 \mathrm{ml}$ of bloody urine.

An intravenous urogram requested showed an absent right kidney and the ureter. The left ureter was present and normal and compensatory hypertrophy of the left kidney was noted with normal calyces. The bladder was normal with no out-pouching. There was however, contrast in the vagina. An ultrasound scan done at the same time confirmed absence of the right kidney and fluid in the vagina. The exact site of the fistulous connection could not be identified on still images (Figures 3 and 4).

Cystoscopy was done a week after the episode of hematuria and showed normal bladder mucosa and no evidence of endometriosis or any tumour. The impression at this stage was that in addition to the transverse septum there were also fistulous connections between the upper vagina and bladder as well as the pouch of Douglas (Figure 5). Karyotyping done
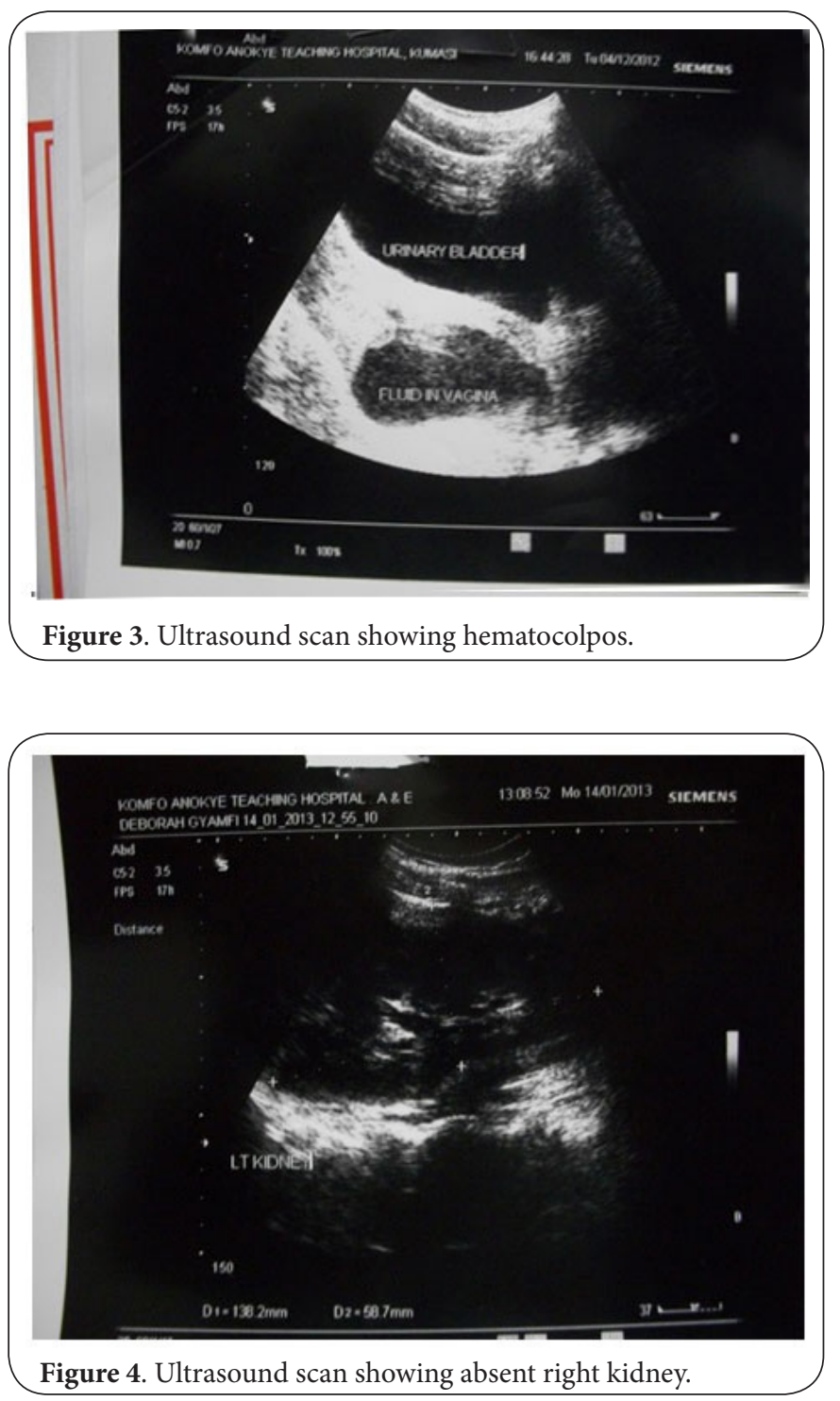


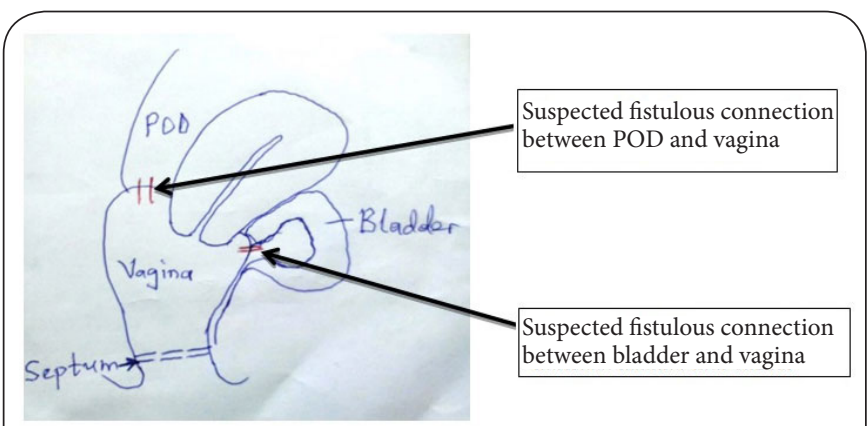

Figure 5. Sketch of suspected pathology before surgery. Red lines indicate points of fistulous connections.

showed 46XX. The patient was counseled and scheduled for surgical correction in a month's time.

\section{Treatment}

Surgery was carried out using both the vaginal and abdominal approaches. One team worked from below, making a Z-incision in the vaginal septum. The distal leaf of the septum was carefully dissected off to reach the proximal leaf which was about $5.0 \mathrm{~mm}$ away. Another team worked from the abdomen through a Pfannenstiel incision to gain access to the fundus uteri. A stab incision was made into the uterus, through which a probe was inserted and advanced into the cervical canal to tent the vaginal septum. The abdominal team manipulated the probe which was felt from below and reached by further incising the proximal leaf of the septum. About 100 milliliters of offensive brownish fluid was drained. The entire circumference of the septum was then excised by the vaginal team after the proximal leaf had been undermined. The cervix was felt to be normal. Remnants of the two leaves were then brought together without tension and sutured in a circumferential manner with vicryl 2-0 sutures. After hemostasis had been achieved, a condom was filled with gauze to about $4.0 \mathrm{~cm}$ diameter and the vagina packed with it (Figure 6). The uterine incision was closed with vicryl ' 0 ' and the abdomen cleaned and closed in two layers with nylon ' 1 ' to the skin. She was

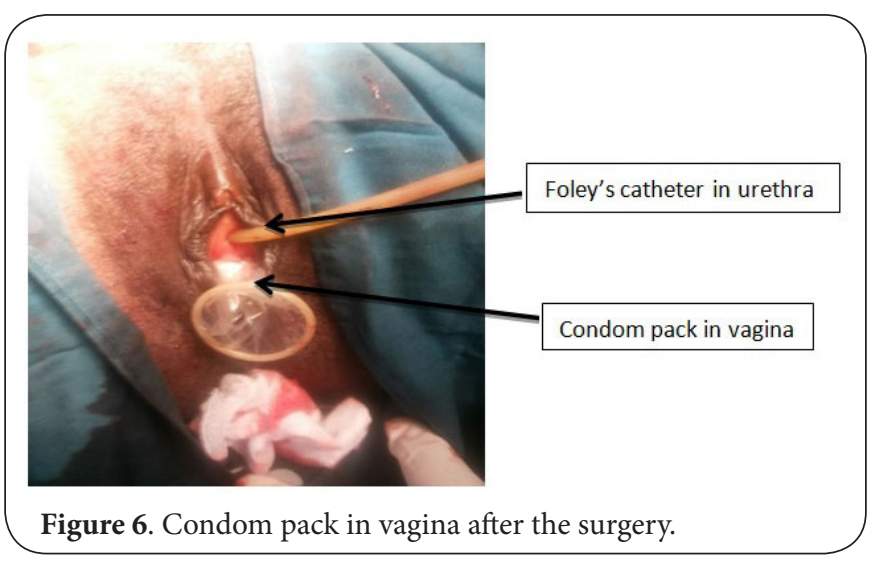

put on broad-spectrum antibiotics for one week.

On the $2^{\text {nd }}$ postoperative day the vaginal pack was removed. The suture line was clean and dry. The vagina was patent, admitting 2 fingers freely to a depth of $8.0 \mathrm{~cm}$. The vagina was cleaned with 'Savlon' and the condom pack replaced. The abdominal stitches were removed on the $5^{\text {th }}$ postoperative day. The condom pack was changed every $3^{\text {rd }}$ day for 2 weeks. She was taught how to change the condom pack every $3^{\text {rd }}$ day, supplied with a pack of condoms and sterile gauze and then discharged home after 15 days.

She had her first normal menses 2 weeks after the surgery and was very happy. There was no associated hematuria. She had weekly vaginal examination under analgesia with diclofenac injection in theatre for 10 weeks, during which the condom packs were replaced. The vagina remained patent. After 12 weeks she was asked to stop inserting the condom packs and to have regular peno-vaginal intercourse. She has since been having her normal menses for the past 15 months with no associated hematuria. The vagina has remained patent since.

\section{Discussion}

We have presented a rather rare case of combined low transverse vaginal septum and vesico-uterine fistula associated with unilateral renal agenesis and imperforate anus. A literature search showed only 15 reported cases [7-10]. Six (6) had unilateral kidneys and ureters. Fistulas were identified between the vagina and bladder in 7 , and between the vagina and urethra in 3 of the cases. Four (4) had persistent urogenital sinus. Ten (10) had upper urinary tract abnormalities (solitary kidneys in 6, duplicated ureters in 1, cystic kidneys in 2 and hypoplastic kidneys in 2). Four (4) cases were associated with skeletal malformations.

The case presented falls into the class of disorders of vertical fusion which also include cervical dysgenesis.

Because of the close relationships during development of the renal and genital systems, anomalies in one system easily results in anomalies of the other. Associated anomalies of transverse vaginal septum include imperforate anus $[6,10]$, which this patient had at birth and for which a 2-staged surgery was done. It is believed that associated congenital vesico-vaginal fistulae are not likely and that the fistulae develop as a result of pressure built up from accumulated menses in the upper vagina proximal to the septum $[7,8]$. This assertion is supported by the fact that in documented cases, after excision of the septum without concomitant correction of the fistulae, the hematuria resolves spontaneously, as happened in this case. As was shown on ultrasound, this patient had fistulae to the bladder as well as to the pouch of Douglas, and these support the belief that they occurred secondary to pressure build-up in the upper vagina from accumulated menstrual blood.

In resource-limited areas such as found in the authors' centre, excision of the transverse septum followed a simple 
Opoku et al. Gynecology 2015,

http://www.hoajonline.com/journals/pdf/2052-6210-3-1.pdf

procedure as described [11]. Although the vaginal approach alone is adequate in excising the septum and correcting the anomaly when a prior vaginal ultrasound has shown the extent of the thickness of the septum, the procedure described was adopted in this patient. This was to avoid excessive dissection from below and avoid any injuries to the ano-rectal tissues especially when this patient had had surgery to correct an imperforate anus as a baby. A stab incision on the fundus of the uterus adequate to just admit a probe was used to minimize post-operative adhesion formation that could affect future fertility. Unilateral renal agenesis is complicated by recurrent urinary tract infections, hypertension and renal stones [12]. This patient had none of these and is being closely monitored.

\section{Conclusion}

Excision of the transverse vaginal septum in such cases that allows free outflow of menstrual blood is adequate to close the fistulous connection between the bladder and upper vagina. Postoperative management is very essential to minimize the risk of scar contracture as the wound heals. The use of replaceable male condom filled with gauze to serve as a vaginal pack for $8-10$ weeks is a simple and readily available measure that is recommended. This must be followed by regular peno-vaginal intercourse to prevent scar contracture.

\section{Competing interests}

The authors declare that they have no competing interests.

\section{Authors' contributions}

\begin{tabular}{|l|c|c|c|}
\hline Authors' contributions & BKO & ROK & PAP \\
\hline Research concept and design & $\checkmark$ & $\checkmark$ & $\checkmark$ \\
\hline Collection and/or assembly of data & $\checkmark$ & $\checkmark$ & $\checkmark$ \\
\hline Data analysis and interpretation & -- & -- & -- \\
\hline Writing the article & $\checkmark$ & $\checkmark$ & $\checkmark$ \\
\hline Critical revision of the article & $\checkmark$ & $\checkmark$ & $\checkmark$ \\
\hline Final approval of article & -- & -- & -- \\
\hline Statistical analysis & -- & -- & -- \\
\hline
\end{tabular}

\section{Acknowledgement}

We greatly appreciate the patient who willingly agreed to have her case presented to advance knowledge in medicine. We also thank Drs Mike Addow, KwadwoSarbeng and AmoAntwi and the nurses who helped manage this patient.

\section{Publication history}

EIC: Christos lavazzo, Gynaecological Oncology Department, Royal Surrey County Hospital, Guildford, Surrey, UK.

Received: 18-Feb-2015 Final Revised: 20-Mar-2015

Accepted: 04-Apr-2015 Published: 14-Apr-2015

\section{References}

1. Mishell DR, Stenchever MA, Droegmuller W and Herbst AL. Eds. Congenital Anomalies of the Female Genital Tract. In Comprehensive Gynecology. Mosby Year Book. 1997; 251.

2. Deppisch LM. Transverse vaginal septum. Histologic and embryologic considerations. Obstet Gynecol. 1972; 39:193-8. I Article I PubMed

3. Rock JA and Azziz R. Genital anomalies in childhood. Clin Obstet Gynecol. 1987; 30:682-96. | Article I PubMed
4. Gell JS. Mullerian anomalies. Semin Reprod Med. 2003; 21:375-88. | Article | PubMed

5. Banerjee R and Laufer MR. Reproductive disorders associated with pelvic pain. Semin Pediatr Surg. 1998; 7:52-61. I Article I PubMed

6. Thompson DP and Lynn HB. Genital anomalies associated with solitary kidney. Mayo Clin Proc. 1966; 41:538-48. I Article I PubMed

7. Genest D, Farber M, Mitchell GW, Jr., Turksoy RN and Rule AH. Partial vaginal agenesis with a urinary-vaginal fistula. Obstet Gynecol. 1981; 58:130-4. I Article | PubMed

8. Verhoeven AT. Primary menouria due to congenital vesicovaginal fistula. Obstet Gynecol. 1973; 41:515-20. I Article I PubMed

9. Daskalov I and Sahpazov M. [Report of a case of congenital vesicouterine fistula with vaginal atresia associated with an exterior uterine cervix and agenesis of the right kidney]. Jugos/ Ginekol Opstet. 1982; 22:78-81. | Article | PubMed

10. Chin Al, Rutman M and Raz S. Transverse vaginal septum with congenital vesical-vaginal communication and cyclical hematuria. Urology. 2007; 69:575. | Article | PubMed

11. Opoku BK, Djokoto R, Owusu-Bempah A and Amo-Antwi K. Huge abdominal mass secondary to a transverse vaginal septum and cervical dysgenesis. Ghana Med J. 2011; 45:174-6. | PubMed Abstract | PubMed Full Text

12. Emanuel $\mathrm{B}$, Nachman $\mathrm{R}$, Aronson $\mathrm{N}$ and Weiss $\mathrm{H}$. Congenital solitary kidney. A review of 74 cases. Am J Dis Child. 1974; 127:17-9. | Article | PubMed

\section{Citation:}

Opoku BK, Kwarteng RO and Prempeh PA. Transverse vaginal septum with menouria and unilateral renal agenesis-case report. Gynecol. 2015; 3:1. http://dx.doi.org/10.7243/2052-6210-3-1 